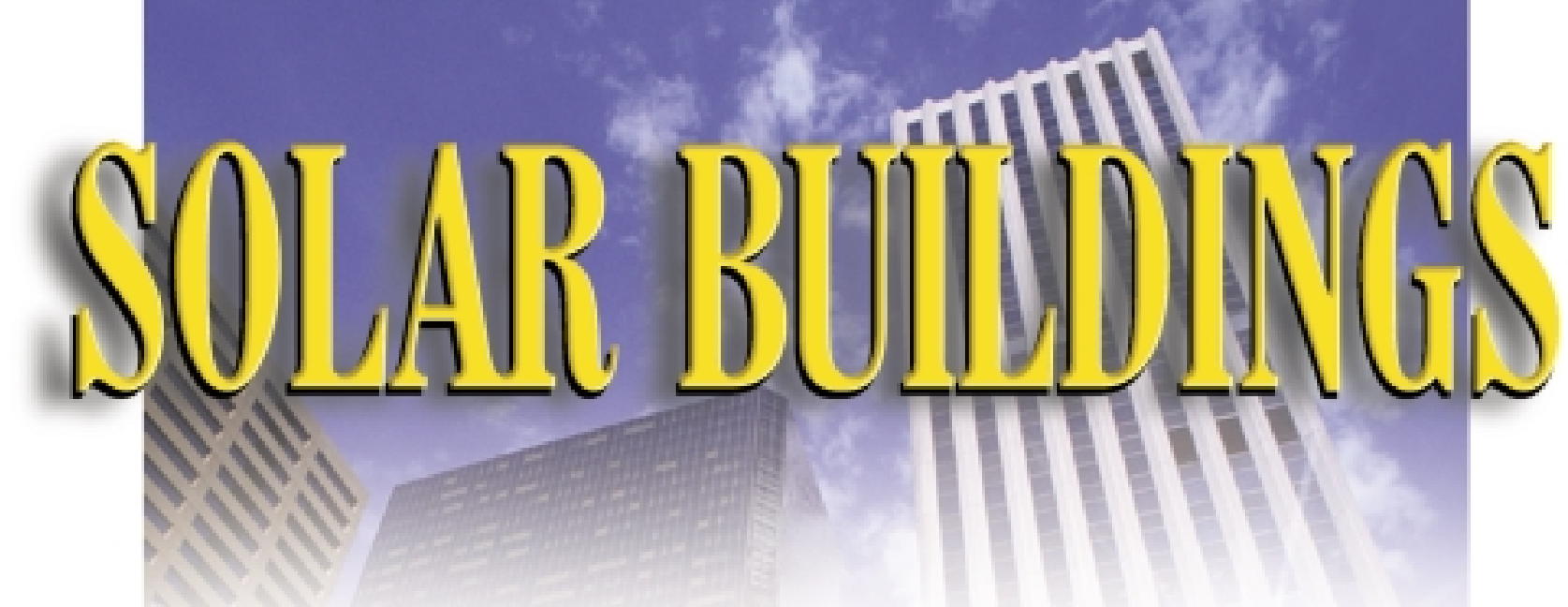

\title{
Overview: The Solar Buildings Program
}

THE PROGRAM

FOCUSES ON

TECHNOLOGIES

THAT HAVE THE

POTENTIAL TO

PRODUCE ECO-

NOMICALLY

COMPETITIVE

ENERGY FOR

THE BUILDINGS

SECTOR.

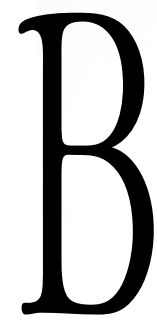

uildings account for more than onethird of the energy used in the United States each year, consuming vast amounts of electricity, natural gas, and fuel oil. Given this level of consumption, the buildings sector is rife with opportunity for alternative energy technologies. The U.S. Department of Energy's (DOE's) Solar Buildings Program was established to take advantage of this opportunity.

The Solar Buildings Program is engaged in research, development, and deployment (RD\&D) on solar thermal technologies, which use solar energy to produce heat. The Program focuses on technologies that have the potential to produce economically competitive energy for the buildings sector. By working closely with manufacturers in the buildings and solar energy industries and by supporting research at universities and national laboratories, the Solar Buildings Program brings together the diverse players developing reliable, economically viable solar thermal technologies for building applications. The Program also works collaboratively with builders, utilities, and energy service companies.

The Solar Buildings Program's solar thermal focus is driven by the need for thermal energy for water heating, space heating and cooling applications, pool heating, and industrial process heating. Researchers within the Program are working on a range of solar thermal technologies that generate hot water and heated air for residential and commercial use. Researchers also are investigating the use of solar technologies in energyintensive agricultural applications, which could have a substantial impact on the technology's export market. In addition, the Program is developing innovative, next-generation solar cooling technology.

Flat-plate collectors used for generating bot water can be integrated into new bome construction.

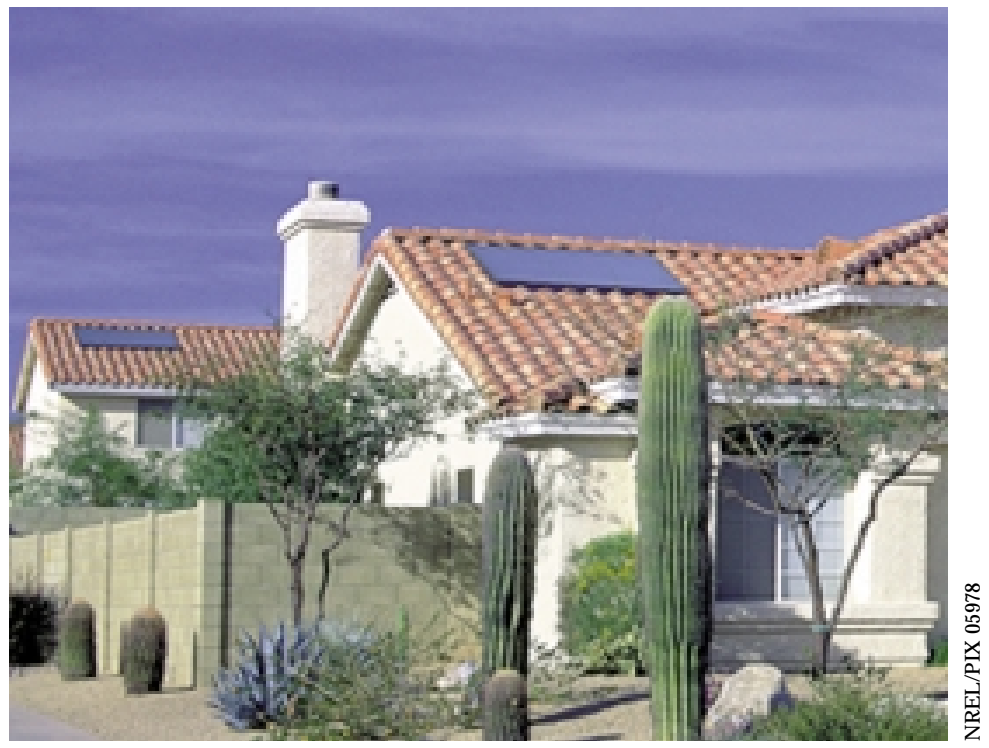




\section{Why Solar Buildings?}

We are all familiar with the environmental and economic benefits of reducing our

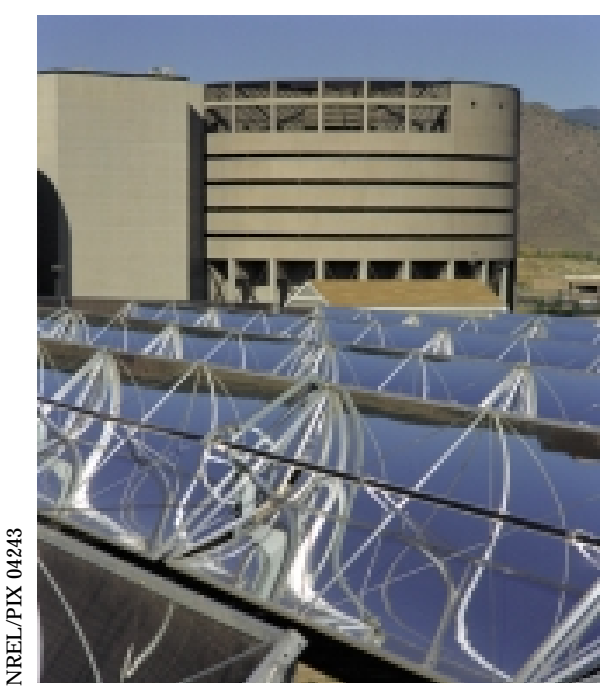

dependency on energy generated by the combustion of fossil fuels. The steps we take today developing alternative, cost-effective energy technologies will pay off tomorrow in increased energy stability and improved environmental quality.

A look at energy consumption within the buildings sector

The solar bot water system at the Jefferson County Jail in Golden, Colorad uses parabolic trough collectors to meet $50 \%$ of the facility's bot water needs.
*These figures were compiled from the following sources: Quantitative Rationale for Active Solar Technology Program, Science Applications International Corporation (1996); Annual Energy Review 1996, DOE/EIA O384(96); Renewable Energy Annual, DOE/EIA O603(96) (1996). demonstrates the importance of continued alternative energy technology development. Of the 94 quadrillion Btus (Quads) of energy consumed annually in the United States, buildings account for 34 Quads, or about 36\%. Residential water heating alone accounts for 2 Quads. Studies estimate 70\% of new homes (approximately 1 million per year) could be designed to accommodate energy-producing solar technologies. By the year 2020, therefore, solar hot water systems could potentially supply 15\%-25\% (0.5 Quads) of the energy used for home water heating.* Although these figures pertain only to residential water heating, they are representative of the impact that solar technology could have on the buildings sector in the coming decades. In addition to these benefits, solar buildings technologies offer a number of other advantages when compared to competing sources of power.

-Energy diversity. By developing solar technology, we diversify our energy supply and reduce our susceptibility to fluctuations in the availability and price of imported fossil fuels.

-Economic development. A mature solar manufacturing and service industry promotes job creation and local economic development.

- Consumer satisfaction. Recent surveys and consumer choice utility programs demonstrate customer preference for clean sources of energy.

- Environmental efficiency. Each solar water heating system reduces carbon emissions by an amount equivalent to the emissions from an automobile.

\section{Solar Thermal Systems and Collector Technologies}

Solar building technologies convert sunlight into usable forms of thermal energy such as hot water and heated air. The key component in all solar building technologies is the collector-the device that converts the sun's radiant energy to heat. In general, most of the collector designs used in buildings applications fall into one of five categories.

-Flat-Plate Collectors-Commonly used in residential and commercial buildings, these collectors convert ambient levels of solar radiation for low-temperature (less than $180^{\circ} \mathrm{F}$ ) water- and air-heating applications. See the photo on page 1.

-Evacuated-Tube Collectors-Similar to flat-plate designs, evacuated-tube collectors employ a vacuum within a glass cylinder to reduce heat loss to the surrounding environment and generate high operating temperatures $\left(170^{\circ}-350^{\circ} \mathrm{F}\right)$.

- Concentrating Collectors-Unlike flat-plate designs, which operate on ambient sunlight, solar trough collectors and compound parabolic concentrating collectors use curved mirrors to concentrate sunlight on the receiver at up to 60 times its normal intensity. These high-temperature systems are used primarily in commercial and industrial applications. See the photo on this page.
THE KEY COMPONENT

IN ALL SOLAR

BUILDING TECHNOLOGIES

IS THE

COLLECTOR. 
- Transpired Solar Collectors-Used to heat large volumes of air, these innovative yet simple collectors are typically installed on a large portion of a building's south-facing wall. Sunlight heats the surface of the collector, which in turn heats air being drawn through the perforations in the collector. See the photo on this page.

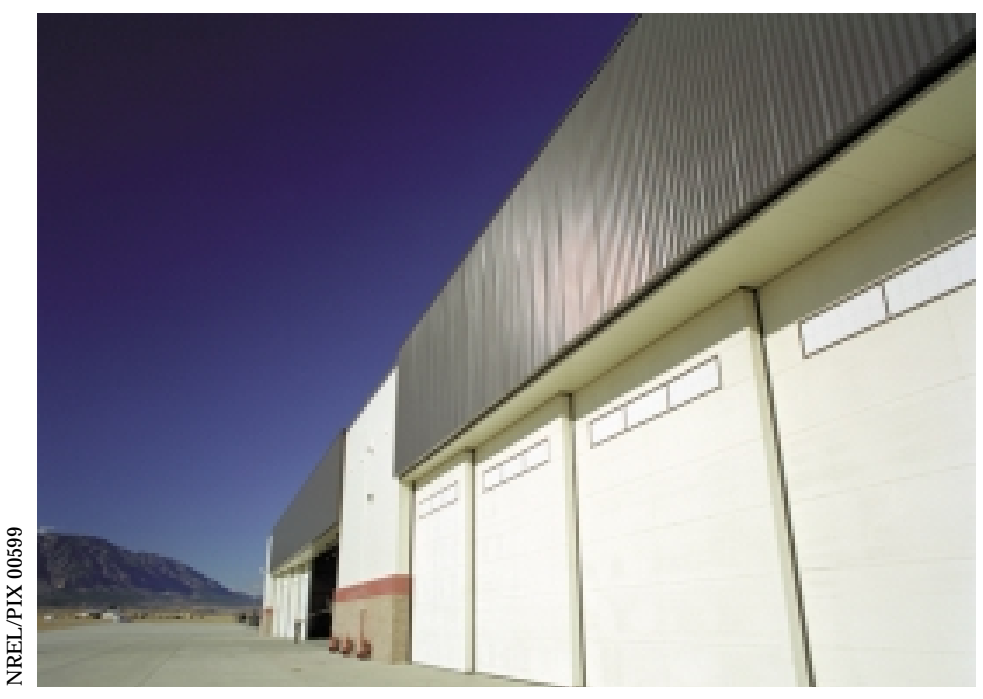

Transpired collectors such as this one on an airplane bangar at Ft. Carson, Colorado, generate large quantities of prebeated ventilation air and are well suited to a variety of commercial and industrial applications.
-Unglazed Flat-Plate Collectors-Commonly used for heating swimming pools, these collectors provide low-temperature energy to lengthen the swimming season.

These solar thermal collector designs can be integrated into a variety of systems to meet specific thermal energy needs. These systems exploit local operating factors such as geographic location, climate, and annual average level of solar radiation. As opposed to passive solar thermal systems-which directly heat air or water-active systems use a heat-transfer medium such as antifreeze or oil to transfer thermal energy from the collector to the enduse load, such as water or space heating.

Active solar systems incorporate mechanical systems to distribute the energy collected. This includes piping, control systems, ductwork, pumps, heat exchangers, fans, and other mechanical components. These are the same components commonly used in the plumbing and heating industries, and they integrate the solar system with a building's conventional heating, ventilating, and air-conditioning system.

Passive systems common in residential water heating merge the solar collector with a storage system. Passive systems are used primarily in areas where the temperature rarely is below freezing. These systems do not incorporate pumps, controllers, or other mechanical components of active systems. They usually are less expensive than active systems, but they generally are less efficient, as well.

\section{DOE's Solar}

\section{Buildings Program: RD\&D on a Broad Front}

The Solar Buildings Program is sponsoring a broad range of RD\&D to bring solar building technologies into wider use. With its focus on technology development, the Program conducts application-oriented RD\&D on established and next-generation solar thermal technologies.

Two DOE national laboratories-the National Renewable Energy Laboratory (NREL) in Golden, Colorado, and Sandia National Laboratories (SNL) in Albuquerque, New Mexico-jointly participate in the Solar Buildings Program. In addition to conducting RD\&D, the two national laboratories work closely with industry and universities to develop technology improvements, reduce manufacturing costs, monitor system performance, and identify potential new markets for solar buildings technologies.

Program researchers are engaged in fundamental technology development in areas such as improved heat-exchange research, advanced coatings for absorbers, and solar cooling. Substantial system cost reductions are being pursued through the development of alternative concepts, such as a polymer-based collector
TWO DOE

NATIONAL

LABORATORIES

JOINTLY

PARTICIPATE

IN THE SOLAR

BUILDINGS

PROGRAM. 
THE

DEVELOPMENT

OF ALTERNATIVE

\section{MATERIALS}

COULD REDUCE

SYSTEMS COSTS

BY UP TO $\mathbf{5 0 \%}$ that could cut life-cycle costs in half.

Researchers are also investigating the use of low-cost solar thermal systems in agricultural applications, such as crop drying. The initial work in this area is focusing on crop-drying processes in Latin America and Africa, where drying is accomplished by burning large amounts of timber. The crop-drying research is part of a larger effort to adapt solar building technology to additional markets, enabling U.S. solar thermal manufacturers to expand exports.

In other development efforts, the Program works closely with the solar and buildings industries to improve manufacturing processes and overcome the barriers to widespread use of solar technologies. Program engineers and SNL and NREL staff are assisting a number of solar manufacturers to streamline their processes and reduce overall system costs by 10\%-20\%.

Program researchers at NREL are conducting a series of workshops and surveys to determine the areas of solar thermal technology development deemed critical by utilities, builders, and consumers. The Program is soliciting this stakeholder feedback to help the solar industry meet developing market trends. NREL and SNL are using the information gathered through these efforts to focus their RD\&D.

In related work, the Program is supporting the DOE's Million Solar Roofs Initiative, which aims to place 1 million solar energy systems on the roofs of homes and buildings across the United States by the year 2010. The Solar Buildings Program contributes to this Initiative by establishing partnerships with related DOE programs, state energy offices, and the National Association of

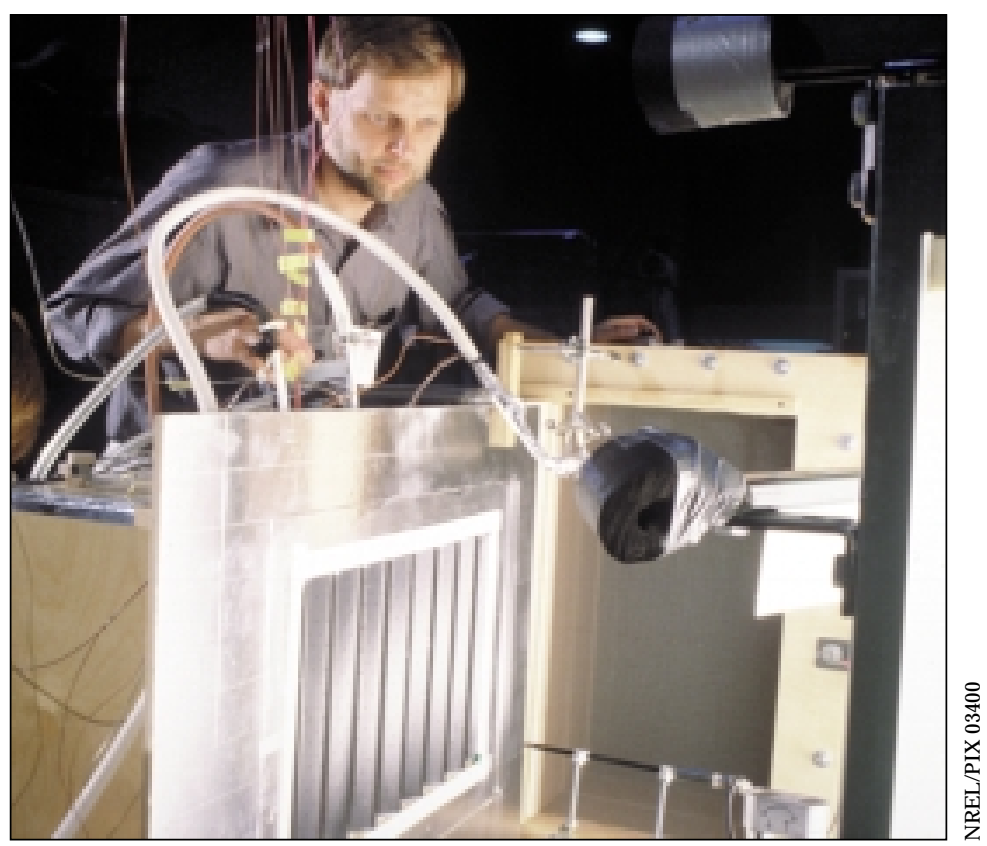

Homebuilders Research Center. It also seeks partnerships with homebuilders and utilities to help them determine the potential of solar energy to meet the needs of their customers.

\section{Summary}

Through its RD\&D in solar thermal technology, DOE's Solar Buildings Program is working toward expanding the use of dependable, cost-effective renewable energy in the buildings sector. The Program welcomes the participation of the solar and building industries, as well as qualified researchers from the academic community. We encourage you to contact us for additional information about the Solar Buildings Program.
A researcher in the Solar Buildings Program uses a wind tunnel to test variations of transpired solar collectors.

\section{Produced for the}

U.S. Department of Energy

1000 Independence Avenue, SW

Washington, DC 20585-0121

by the

National Renewable

Energy Laboratory,

a DOE national laboratory
Visit the Solar Buildings Program web site: www.eren.doe.gov/solarbuildings

DOE/GO-10098-552

April 1998

Printed with renewable-source ink on paper containing at least $50 \%$ wastepaper, including $20 \%$ postconsumer waste 